\title{
Effects of Antral Distension on Pancreatic Exocrine Secretion in Dogs: Evidence for a Short Reflex
}

\author{
Naohiro Furukawa and Hiromasa OKADA \\ Department of Physiology, Kawasaki Medical School, \\ Kurashiki, 701-01 Japan
}

\begin{abstract}
In chloralose anesthetized dogs and decerebrated dogs whose pyloric sphincter was submucosally ligated, the pancreatic exocrine secretory response to antral distension was studied. Distensions of the antral pouch with Tyrode's solution and $0.1 \mathrm{~N} \mathrm{HCl}$ caused graded rises in pancreatic flow and protein and bicarbonate outputs. The serum gastrin concentration gradually rose after the distension with Tyrode's solution, while no rise in serum gastrin was elicited by acid distension. After cervical vagotomy, a reduced pancreatic response persisted but no rise in the serum gastrin was seen. After splanchnicectomy following vagotomy, the pancreatic response became greater than before splanchnicectomy. This pancreatic response was observed even after caeliac and superior mesenteric ganglionectomies, but was completely abolished by an external tight ligature around the pyloric sphincter, or by administration of hexamethonium or atropine sulfate. The results suggest the existence of an antropancreatic short reflex in addition to a long route vago-vagal reflex.
\end{abstract}

Key words: antro-pancreatic reflex, exocrine secretion, vagotomy, splanchnicectomy, gastrin.

White et al. (1960) found that distension of the gastric corpus in conscious dogs caused an increase in pancreatic secretion via the vago-vagal reflex. DEBas and YAMAGISHI (1978) reported that distension of the pyloric antrum in conscious dogs caused an increase in pancreatic secretion mainly through the vago-vagal reflex and partly through a rise in the serum gastrin concentration. DeBas and YAMAGISHI (1978) stated that acid distension of the pyloric antrum caused no rise in pancreatic secretion after truncal vagotomy.

The gastropancreatic reflexes have not been reported in anesthetized dogs or decerebrated dogs. Most anesthetics markedly diminish both the nervous activity and pancreatic response to a given stimulus. However, BABKIN (1924) has stated that chloralose is a very suitable narcotic for the study of the pancreatic secretion.

Received for publication April 23, 1987 
BLAIR et al. (1966) showed that, in chloralose anesthetized cats, antral and body distension of the stomach caused a rise in amylase output from the pancreas but not in the pancreatic flow.

In the course of experiments on mucosal chemical stimulation of the canine pyloric antrum (OKADA and FURUKAWA, 1984), we noticed that a short reflex from the antrum to the pancreas may participate in evoking secretion from the pancreas. The present study was undertaken to elucidate the participation of this short reflex. Parts of the results have been reported elsewhere (FURUKAWA and OKADA, 1985).

\section{MATERIALS AND METHODS}

Animal preparations. Experiments were performed on 44 mongrel dogs (5$12 \mathrm{~kg}$ ) fasted $18 \mathrm{~h}$ before surgery. Thirty-four dogs were anesthetized with ketamine $(10 \mathrm{mg} / \mathrm{kg}$, i.m.) and $\alpha$-chloralose $(60 \mathrm{mg} / \mathrm{kg}$, i.v.). Ten dogs were decerebrated at the level of the rostral end of the superior colliculus under ketamine anesthesia ( $10 \mathrm{mg} / \mathrm{kg}$, i.m.). All dogs were paralyzed with gallamine triethiodide ( $2 \mathrm{mg} / \mathrm{kg}$, i.v.), and a midline abdominal incision was made under artificial ventilation. In all dogs, the pyloric sphincter was occluded by submucosal ligature to prevent gastric fluid flow into the duodenum. This was done by passing a string submucosally through the pyloric sphincter to avoid interference with innervation and blood supply. After experiments, the occlusion was secured by intraantral infusion of $50 \mathrm{ml}$ of dye solution. The accessory pancreatic duct was occluded. A vinyl cannula was inserted into the main pancreatic duct through a small incision in its wall near the opening to collect pancreatic juice. The cannula was $1.5 \mathrm{~mm}$ in outer diameter and about $15 \mathrm{~cm}$ in length. A force transducer was sewn on the wall of the gastric corpus in the direction of the circular muscles. To separate the anrum region from the gastric corpus, a plastic cylinder ( $3 \mathrm{~cm}$ in diameter, $4 \mathrm{~cm}$ in length) with a septum, through the center of which a vinyl tube was passed, was inserted through an incision in the proximal part of the stomach. The gastric wall was then ligated at the junction of the body and antrum, care being taken to avoid interfering with the innervation and blood supply in the same manner as in the pyloric ligature. Finally, the abdominal cavity was closed. The central tube of the cylinder was used for both antral distension and recording of antral motility by leading it to a pressure transducer (Nihon Kohden: MPU-290-0-III). In some cases, antral and descending duodenum movements were recorded using a force transducer. Systemic arterial pressure in the right femoral artery and gut motility were recorded simultaneously on a multichannel pen-writing recorder by using pressure transducers.

Experimental design. Twenty-eight dogs (18 anesthetized and 10 decerebrated) were used to analyze the effect of antral distension on pancreatic secretion before vagotomy.

To examine the role of vagal nerve in the pancreatic response, cervical vagotomy was done in 18 dogs at the mid cervical regions (15 anesthetized and 3 decerebrated dogs). In 4 dogs which showed only small basal pancreatic secretion 


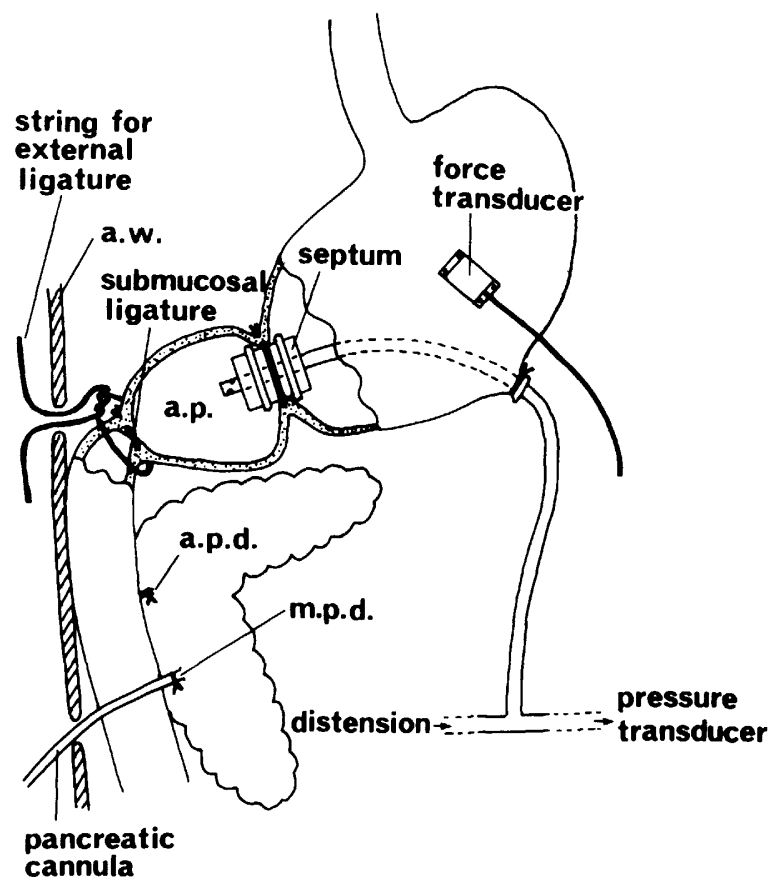

Fig. 1. Schematic representation of the animal preparation. a.p., antral pouch; a.p.d., accessory pancreatic duct; a.w., abdominal wall; m.p.d., main pancreatic duct.

after cervical vagotomy, a small dose of secretin (Boots) was injcted continuously through the right femoral vein at a rate of $0.1-0.2 \mathrm{unit} /(\mathrm{kg} \cdot \mathrm{hr})$, using a variable rotary pump (Yamato: PA-21A).

In 12 dogs, the effect of splanchnicectomy subsequent to vagotomy was examined. For this series of experiments, the bilateral lumber sympathetic chains were extraperitoneally removed, the right splanchnic nerve was cut, and the left splanchnic nerve was exposed in preparation for later cutting. This extraperitoneal approach was attained by bilateral paravertebral longitudinal incisions through a 15$\mathrm{cm}$ length caudal of the costovertebral triangle and by cutting along the membranous ligamens of the external and internal abdominal oblique muscles.

To clarify the role of the nerves passing across the seromuscular layer of the pyloric sphincter, the pyloric sphincter was cut in $1 \mathrm{dog}$ and ligated from the serosal side in 2 dogs. In 4 dogs, a string was loosely looped around the pyloric sphincter, and both ends of it were led outside of the body through a small incision in the right epigastric region to avoid reduction of antral motility due to exposure of the stomach to air (Fig. 1).

In 2 vagotomized and splanchnicectomized dogs, caeliac and superior mesenteric ganglions and the periarterial nerve fibers around the caeliac and superior mesenteric arteries were extraperitoneally removed through the paravertebral 
approach described above. After the experiment, removal of the ganglions and periarterial nerve fibers were confirmed by microscopic observation.

In 6 other vagotomized dogs, maximal levels of pancreatic flow and protein output were estimated by giving each a bolus injection of 4 units $/ \mathrm{kg}$ of secretin (Eisai) and 8 units/kg of CCK-PZ (Boots) into the right femoral vein.

Determinations of pancreatic protein and bicarbonate. The drops (approximately $0.01 \mathrm{ml}$ ) from the pancreatic cannula were counted by a photodetective counter and its output was led to a multichannel recorder. Every 10 or 20 drops of the pancreatic juice were collected, and diluted to $1 / 50-1 / 200$ with $0.9 \% \mathrm{NaCl}$ solution. The protein concentration was estimated by measuring absorbance at $280 \mathrm{~nm}$, using a double-beam spectrophotometer (Hitachi: 100-60) and employing bovine serum albumin as the standard. The protein concentration was used as an index of pancreatic enzyme secretion. The bicarbonate concentration was measured by adding $1.0 \mathrm{ml}$ of $0.1 \mathrm{~N} \mathrm{HCl}$ to the diluted pancreatic juice, boiling the mixture for a few minutes, and when cooled, back-titrating the residual acid to $\mathrm{pH} 7.0$ with $0.1 \mathrm{~N}$ $\mathrm{NaOH}$, using a $\mathrm{pH}$-stat (Radiometer: RTS-6).

Determination of serum gastrin. In $12 \mathrm{dogs}, 2.5-3.0 \mathrm{ml}$ blood samples were collected every $5-10 \mathrm{~min}$ through the left femoral vein. The blood samples were reserved for $30-60 \mathrm{~min}$, and the serum was separated by centrifugation at 2,000 $3,000 \mathrm{rpm}$. The serum samples were stored in a refrigerator until assay. Serum gastrin concentrations were immunochemically determined by Ostuka Assay Laboratories, using a gastrin-kit II (Dinabot) which cross-reacts with total gastrin.

Distension experiments. Distension experiments were performed $2-3 \mathrm{~h}$ after the operation under artificial ventilation. For the antral distensions, $10-50 \mathrm{ml}$ of Tyrode's solution (145.4 mM NaCl, $4.8 \mathrm{~mm} \mathrm{NaHCO}, 2.7 \mathrm{~mm} \mathrm{KCl}, 1.5 \mathrm{~mm} \mathrm{CaCl}_{2}$, $0.7 \mathrm{mM} \mathrm{MgCl}_{2}, 0.3 \mathrm{~mm} \mathrm{NaH} \mathrm{PO}_{4}, \mathrm{pH}=7.4$ ) or $0.1 \mathrm{~N} \mathrm{HCl}$ was placed in the antral pouch for $15 \mathrm{~min}$. Almost all of the distensions were interposed by a more than 20 min "rest" period.

Statistical analysis. The magnitudes of pancreatic responses to 2 or 3 distensions were averaged. The protein and bicarbonate outputs for each 2.5- or 5min period were calculated by multiplying the volume. The statistical significance of differences between mean basal pancreatic secretion and mean pancreatic response to antral distension was analyzed by Student's $t$-test for paired data. $p$ values of less than 0.05 were considered as significant.

\section{RESULTS}

\section{1) Pancreatic response to antral distension before vagotomy}

In 25 of $28 \mathrm{dogs}$, antral distension with Tyrode's solution $(10-40 \mathrm{ml}$, about $15 \mathrm{~min}$ ) caused a rise in pancreatic flow with a latency of 1 to $4 \mathrm{~min}$. The pancreatic flow increased from a control value of $29.0 \pm 4.7$ (range 6-128) to $83.7 \pm 19.0$ (range 17-569) $\mu \mathrm{l} / 5 \mathrm{~min}$, on the average (mean \pm S.E.) during the first 5 to $10 \mathrm{~min}$ following the distension. An example of the marked response in the anesthetized dogs is given 


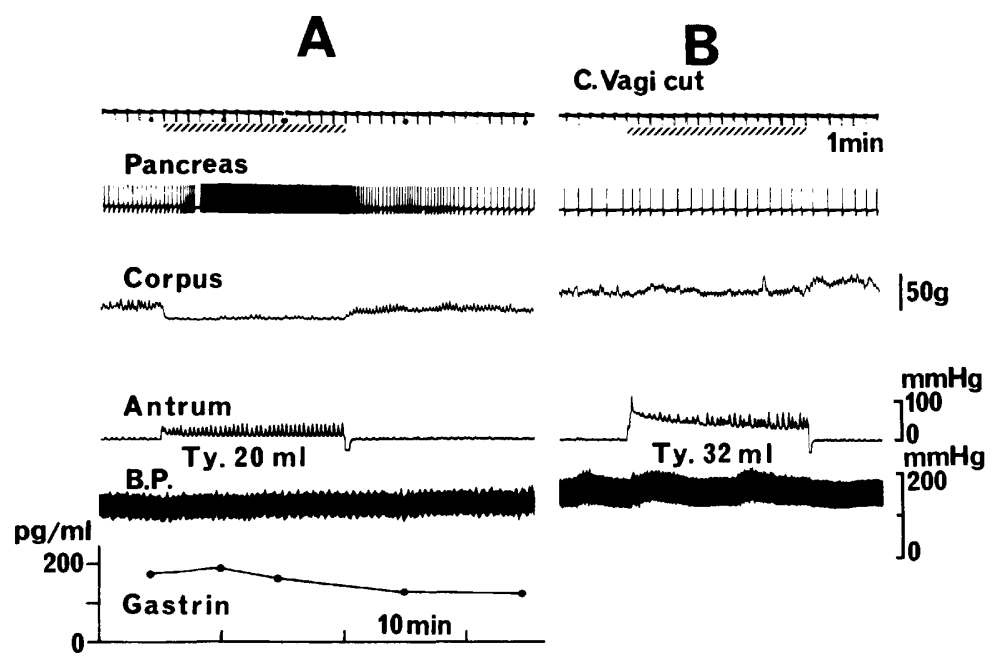

Fig. 2. Pancreatic responses to antral distension before and after cervical vagotomy. Anesthetized dog. A: pancreatic response to antral distension before vagotomy. B: response after cervical vagotomy in the same dog. Time marks at the top of the figure indicate 1-min intervals. Hatched bars indicate the period of antral distension. Ty. and numbers below the intraantral pressure indicate volumes of infused Tyrode's solution. Pancreatic flow rates in A before and during distension were 128 and $569(5-10-\mathrm{min}$ period) $\mu \mathrm{l} / 5 \mathrm{~min}$, respectively. Those in B were 40 and $54(0-5-$ $\min$ period) $\mu \mathrm{l} / 5 \mathrm{~min}$.

in Fig. 2A. The magnitude of the response varied considerably among individual animals. However, graded antral distension generally caused a graded rise in pancreatic flow, which disappeared within 5 min after the cessation of distension. This graded rise in the pancreatic flow was accompanied by a graded rise in protein and bicarbonate outputs. The protein and bicarbonate outputs increased from control values of $6.2 \pm 0.9$ (range $2.2-17.7$ ) $\mathrm{mg} / 5 \mathrm{~min}$ and $1.7 \pm 0.7$ (range $0.1-12.8$ ) $\mu \mathrm{Eq} / 5 \mathrm{~min}$, respectively, to $20.5 \pm 5.1$ (range $4.1-84.9$ ) $\mathrm{mg} / 5 \mathrm{~min}$ and $10.2 \pm 3.0$ (range $0.4-83.1) \mu \mathrm{Eq} / 5 \mathrm{~min}$ during the first 5 to $10 \mathrm{~m}$ in following the distension. The mean values of pancreatic flow, protein and bicarbonate outputs per 5-min period before and during distensions are given in Fig. 3A. Almost all values were significantly higher during the $0-25-\min$ period $(p<0.05)$ than before distensions. Accompanying these pancreatic responses, serum gastrin concentration gradually rose until 20-30 min after initiation of the distension. In 8 dogs, the mean value of the gastrin concentration was $97.3 \pm 14.5$ (range $72.8-174.0$ ) $\mathrm{pg} / \mathrm{ml}$ before distension, and it increased to $135.7 \pm 30.5$ (range $85.7-199.7) \mathrm{pg} / \mathrm{ml} 20 \mathrm{~min}$ after initiation of the distension. The elevated concentration continued $40 \mathrm{~min}$ after the cessation of distension, when the pancreatic responses disappeared, although these rises in gastrin concentration were not significant $(0.1<p<0.05)$. Such pancreatic responses to antral distension were recognized in both anesthetized dogs and decerebrated 

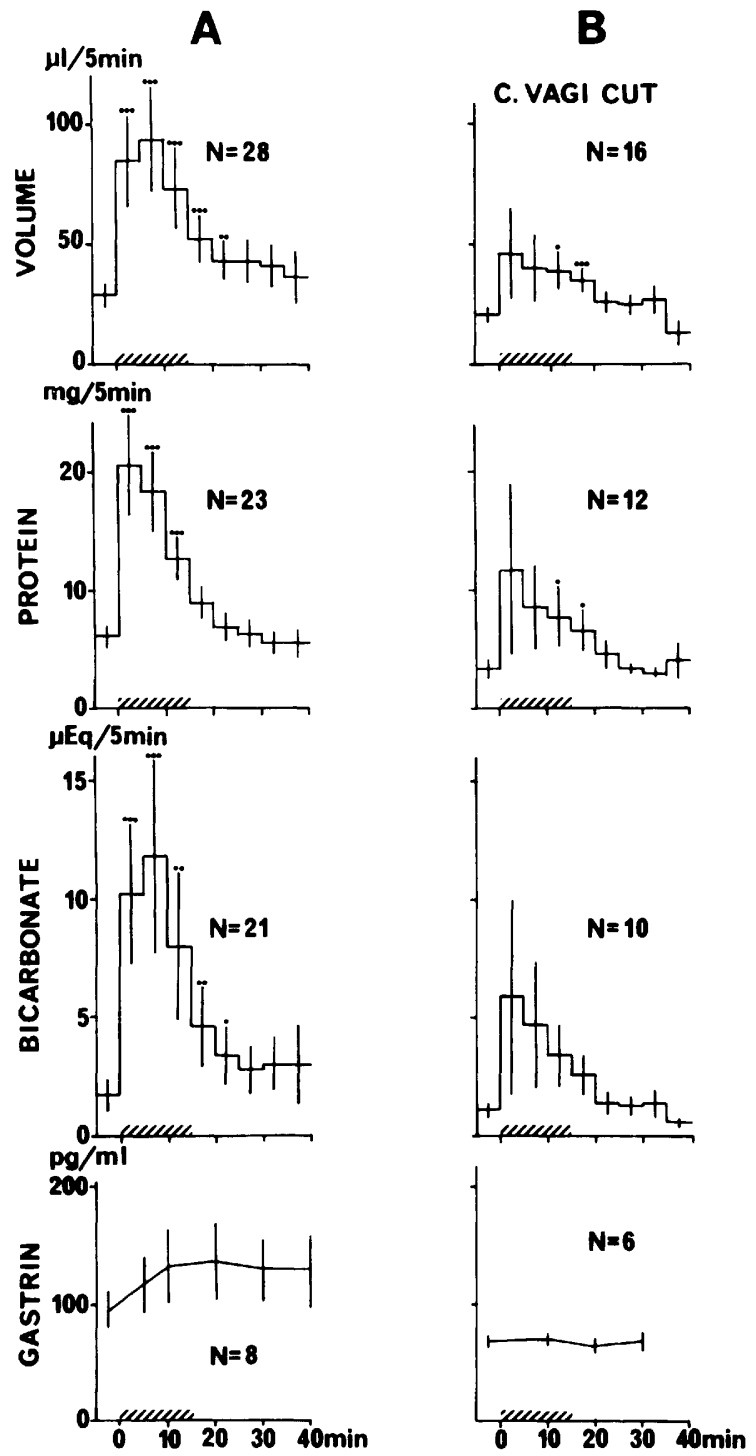

Fig. 3. Effects of cervical vagotomy on pancreatic and gastrin responses to antral distension with Tyrode's solution. A: mean responses in vagi intact dogs. B: mean responses in vagotomized dogs. Means \pm S.E. of the means are given. Hatched bars indicate the period of antral distension. $N$ shows the number of dogs. $* p<0.05$, $* * p<0.02, * * * p<0.01 . p$ values indicate the significance of the difference between the values before distension and in response to distension. 
Table 1. Comparison of pancreatic responses between acid distension and Tyrode distension.

\begin{tabular}{|c|c|c|c|c|c|c|}
\hline & \multicolumn{2}{|c|}{ Volume $(\mu \mathrm{l} / 5 \mathrm{~min})$} & \multicolumn{2}{|c|}{ Protein $(\mathrm{mg} / 5 \mathrm{~min})$} & \multicolumn{2}{|c|}{$\begin{array}{l}\text { Bicarbonate } \\
(\mu \mathrm{Eq} / 5 \text { min })\end{array}$} \\
\hline & Control & Distension & Control & Distension & Control & Distension \\
\hline Tyrode & $28.3 \pm 6.0$ & $70.3 \pm 22.4$ & $7.9 \pm 2.1$ & $18.5 \pm 4.3$ & $0.6 \pm 0.2$ & $4.2 \pm 2.9$ \\
\hline $0.1 \mathrm{~N} \mathrm{HCl}$ & $25.8 \pm 8.2$ & $67.5 \pm 23.7$ & $4.8 \pm 0.9$ & $14.2 \pm 4.3$ & $0.7 \pm 0.4$ & $5.2 \pm 2.8$ \\
\hline
\end{tabular}

Means \pm S.E. obtained from the same four dogs are shown. Mean values of 5-10-min periods are given in the distension column. There were no significant differences between the values in Tyrode distension and the values in acid distension.

dogs, but no definite difference was noted for the basal pancreatic flow and the pancreatic response between these two groups.

Antral distensions were carried out in 4 dogs with $0.1 \mathrm{~N} \mathrm{HCl}$ solution (acid distension) to prevent a gastrin release from the antrum. The increased pancreatic response to antral distension was obtained without a rise in gastrin. The pancreatic flow, protein output and bicarbonate output increased from control values of $25.8 \pm 8.2$ (range 9-48) $\mu \mathrm{l} / 5 \mathrm{~min}, 4.8 \pm 0.9$ (range $2.7-7.0$ ) $\mathrm{mg} / 5 \mathrm{~min}$, and $0.7 \pm 0.4$ (range $0.2-1.9$ ) $\mu \mathrm{Eq} / 5 \mathrm{~min}$, respectively, to $67.5 \pm 23.7$ (range $27-105$ ) $\mu \mathrm{l} / 5 \mathrm{~min}$, $14.2 \pm 4.8$ (range $6.0-24.4$ ) $\mathrm{mg} / 5 \mathrm{~min}$, and $5.18 \pm 2.33$ (range $0.4-19.8$ ) $\mu \mathrm{Eq} / 5 \mathrm{~min}$ during distension. No significant difference in the pancreatic response between the acid distensions and the Tyrode distensions with the same volumes in the same 4 dogs was detectable (Table 1).

\section{2) Pancreatic response to antral distension after cervical truncal vagotomy}

Distension with Tyrode solution was carried out in 16 of 18 vagotomized dogs, and acid distension was carried out in the remaining 2 . Twenty to $50 \mathrm{ml}$ Tyrode distensions in 13 dogs and $30-50 \mathrm{ml}$ acid distensions in 2 dogs caused increased pancreatic secretion. After vagotomy, basal pancreatic secretion was decreased, and the pancreatic response to antral distension was also greatly reduced (Fig. 2B), but in some instances a markedly increased response occurred. The mean values of pancreatic flow, protein output, and bicarbonate output per 5-min period before and during Tyrode distension in vagotomized dogs are given in Fig. 3B. The pancreatic responses were reduced by vagotomy, but the pancreatic flow and protein output were still increased significantly $(p<0.05)$ during distension. The pancreatic flow, protein output, and bicarbonate output increased from control values of $20.7 \pm 2.6$ (range $9-46$ ) $\mu \mathrm{l} / 5 \mathrm{~min}, 3.51 \pm 0.7$ (range $1.2-8.2$ ) $\mathrm{mg} / 5 \mathrm{~min}$, and $1.0 \pm 0.3$ (range $0.2-2.1$ ) $\mu \mathrm{Eq} / 5 \mathrm{~min}$, respectively, to $45.7 \pm 18.7$ (range 15-310) $\mu \mathrm{l} / 5 \mathrm{~min}, 11.8 \pm 7.2$ (range $2.7-89.9$ ) $\mathrm{mg} / 5 \mathrm{~min}$, and $5.9 \pm 4.1$ (range $0.3-42.7$ ) $\mu \mathrm{Eq} / 5 \mathrm{~min}$ during distension. On the other hand, no increase in the gastrin 
concentration in the serum was elicited by the Tyrode distension. So, the results from distensions with Tyrode and acid were analyzed together, and are shown in Fig. 5A.

In 3 of 16 dogs, which underwent Tyrode distensions with a small volume (17$27 \mathrm{ml}$ ), there was no effect on the pancreatic flow.

\section{3) Pancreatic response to antral distension after splanchnicectomy following vagotomy}

Twelve dogs under went splanchnicectomy and removal of the bilateral lumber sympathetic chains after the vagotomy (denervated dogs). The pyloric sphincter was occluded by submucosal ligature in 9 of them. Antral distension with Tyrode was carried out in 3 of $9 \mathrm{dogs}$, distension with acid in 4 of 9 , and both distensions in the remaining 2 dogs. In all dogs, antral distension caused a marked rise in pancreatic secretion (Fig. 4A) that was significantly higher after splanchnicectomy than before (Fig. 5B). The mean values of pancreatic flow, protein output and bicarbonate output per 5-min period before and during distension in such denervated dogs are given in Fig. 5. Almost all values were significantly higher $(p<0.02)$ during the 0 $20 \mathrm{~min}$ period than those before distension. The pancreatic flow, protein output, and bicarbonate output were increased from control values of $17.7 \pm 3.6$ (range 743) $\mu \mathrm{l} / 5 \mathrm{~min}, 4.6 \pm 0.5$ (range $1.8-6.8$ ) $\mathrm{mg} / 5 \mathrm{~min}$, and $0.7 \pm 0.3$ (range $0.2-3.2$ ) $\mu \mathrm{Eq} / 5 \mathrm{~min}$, respectively, to $86.0 \pm 10.9$ (range $18-182$ ) $\mu \mathrm{l} / 5 \mathrm{~min}, 19.3 \pm 3.8$ (range

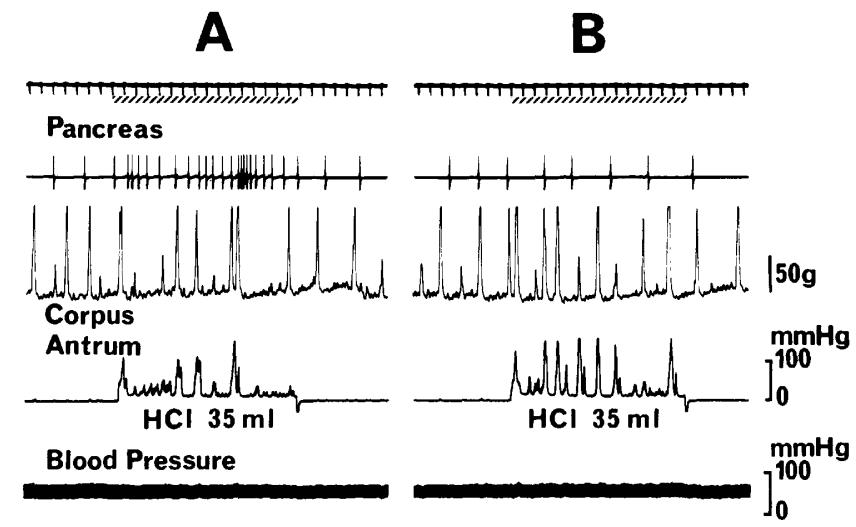

Fig. 4. Pancreatic responses to antral distension before and after the external ligature around the pyloric sphincter in vagotomized and splanchnicectomized dog. Anesthetized dog. A: pancreatic response to antral distension after cervical vagotomy and splanchnicectomy. B: response after additional external ligature around the pyloric sphincter from the serosal side. A and B were obtained from the same dog in which the pyloric sphincter was previously occluded with submucosal ligature. The abbreviations are the same as in Fig. 2. Pancreatic flow rates in A before and during distension are 20 and $93(10-15-\mathrm{min}$ period) $\mu 1 / 5 \mathrm{~min}$, respectively. Those in B were 20 and $16(5-10-\mathrm{min}$ period) $\mu \mathrm{l} / 5 \mathrm{~min}$. 
A
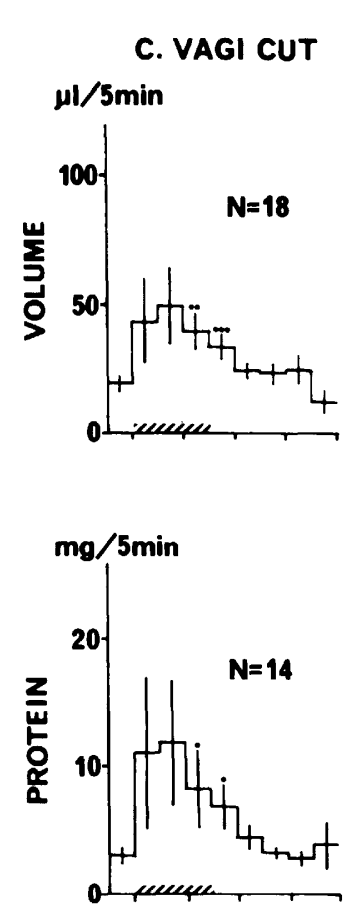

B

$$
\begin{aligned}
& \text { C. VAGI }>\text { SUT } \\
& \text { SPAAN. }
\end{aligned}
$$
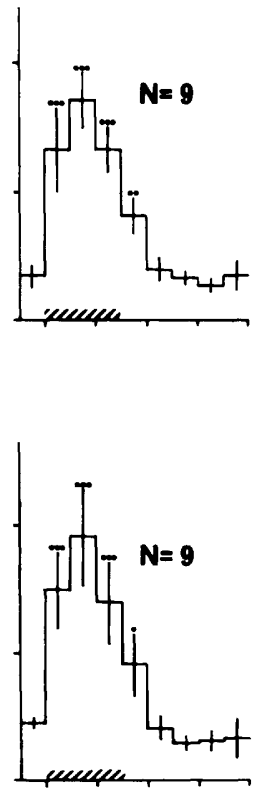

C

\section{c. VAGI}

SPLAN >CUT

PYRO. LIG.

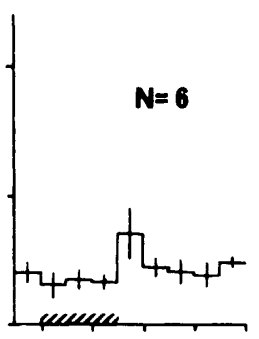

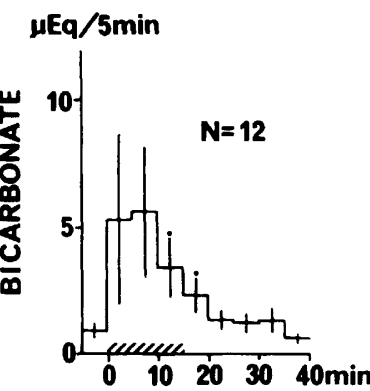
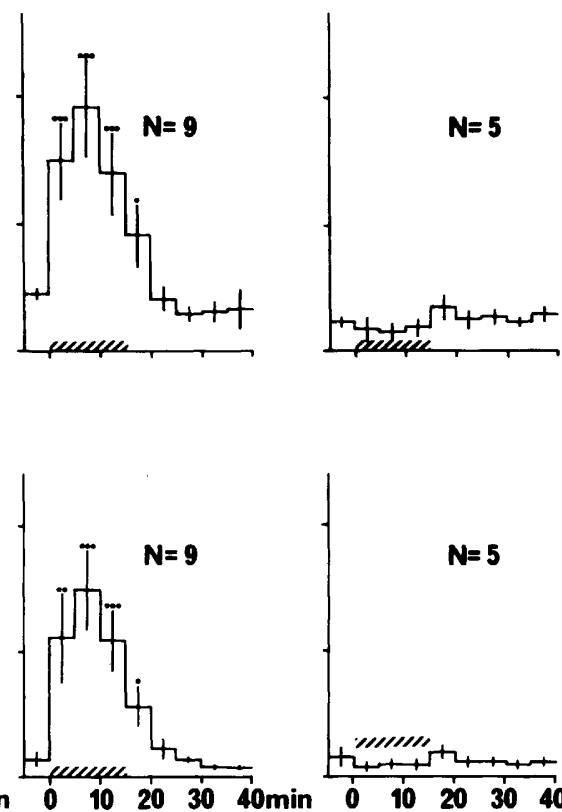

Fig. 5. Effects of splanchnicectomy and external ligature around the pyloric sphincter on pancreatic responses to antral distension. A: mean responses to antral distension with both Tyrode and acid in vagotomized dogs. B: mean responses after additional splanchnicectomy. $\mathrm{C}$ : mean responses after additional external ligature around the pyloric sphincter. The abbreviations are the same as in Fig. 3.

5.9-36.1) $\mathrm{mg} / 5 \mathrm{~min}$, and $7.4 \pm 1.6$ (range $1.4-13.6$ ) $\mu \mathrm{Eq} / 5 \mathrm{~min}$ during distension. These values of pancreatic flow and protein output during distension were about 9 and $24 \%$ of the maximal secretion by exogenous secretin of 4 units $/ \mathrm{kg}$ 
$(936 \pm 108 \mu \mathrm{l} / 5 \mathrm{~min})$ and $\mathrm{CCK}$ of 8 units $/ \mathrm{kg}(81.6 \pm 13.8 \mathrm{mg} / 5 \mathrm{~min})$, respectively.

These effects on pancreatic secretion in such denervated dogs were completely abolished by administration of atropine sulfate $(0.3-0.5 \mathrm{mg} / \mathrm{kg}$, i.v. $)$ in $3 \mathrm{dogs}$ examined and hexamethonium ( $2 \mathrm{mg} / \mathrm{kg}$, i.v.) in 2 dogs examined. In 2 denervated dogs, caeliac and superior mesenteric ganglionectomies were carried out. After these ganglionectomies, a markedly increased pancreatic flow during distension still occurred. In all 4 dogs examined, however, it was abolished by an external ligature around the pyloric sphincter from the serosal side (Fig. 4B), and it did not occur in three dogs whose pyloric sphincter was completely divided from the duodenum or tightly ligated from the serosal side, previously. The values of pancreatic flow, protein output, and bicarbonate output before and during distension are given in Fig. 5C. No significant response was recognized in any of the values. Occasionally,

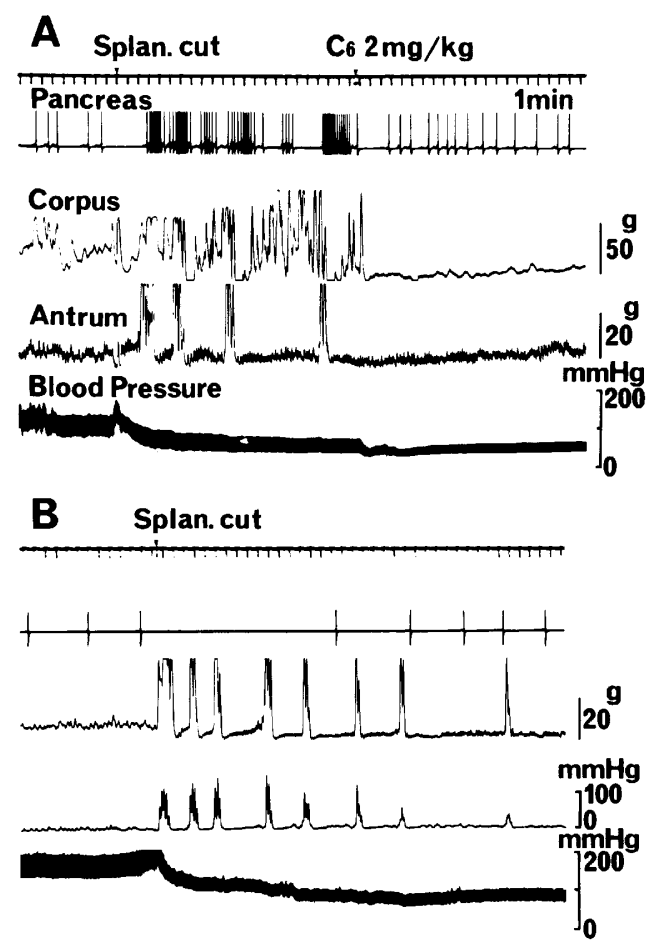

Fig. 6. Effects of splanchnicectomy, hexamethonium, and pyloric section on the pancreatic secretion and spontaneous antral contractions in vagotomized dogs. A: in an anesthetized dog in which the pyloric sphincter was previously occluded with submucosal ligature. B: in an anesthetized dog in which the pyloric sphincter was previously completely divided from the duodenum. Marks above the time scale in A (left) and B indicate the points of the left splanchnicectomy. In both dogs, the bilateral cervical vagus nerve and the right splanchnic nerve were previously sectioned, and bilateral lumbar sympathetic chains were removed. The right mark in $\mathrm{A}$ indicates the administration of hexamethonium (i.v.). 
when the antrum was distended, the flow rate decreased slightly, but this decrease may have been a result of the distended viscus mechanically impeding drainage from the pancreas.

4) Rhythmic pancreatic secretion following spontaneous forceful antral contractions which occurred after splanchnicectomy

In 9 of 14 vagotomized dogs, splanchinicectomy induced marked rhythmic contractions in antral motility. The movements were followed by phasic rises in pancreatic secretion with a latency of 20-30s (Fig. 6A). Such phasic rises in pancreatic secretion were independent of contractions of the gastric corpus and the duodenum. They were frequently recognized when marked pyloric contractions over about $50 \mathrm{mmHg}$ in the intraluminal pressure occurred. Such responses in the movements and flow were abolished by administration of hexamethonium $(2 \mathrm{mg} / \mathrm{kg}$, i.v. ) in 2 dogs examined, and atropine sulfate $(0.3 \mathrm{mg} / \mathrm{kg}$, i.v. $)$ in $2 \mathrm{dogs}$ examined. Further, these phasic rises in the flow were abolished by a tight ligature on the pyloric sphincter from the serosal side in 2 others, while the marked antral contractions were maintained. In 3 dogs whose pyloric sphincter was completely divided from the duodenum or tightly ligated from the serosal side, previously, splanchnicectomy did not induce such increases in the pancreatic flow in spite of the occurrence of marked pyloric contractions (Fig. 6B).

\section{DISCUSSION}

The results of the present study show that antral distension causes a rise in pancreatic secretion in both anesthetized dogs and decerebrated dogs. Undoubtedly a long route vago-vagal reflex plays an important role in the antropancreatic reflex, since the pancreatic response is greatly reduced after cervical truncal vagotomy, as shown by Debas and Yamagishi (1978) in conscious dogs. Further, it was demonstrated in the present study that acid distension after vagotomy causes increased pancreatic secretion without an increase in the gastrin level in serum. This response occurs even after splanchnicectomy in addition to the vagotomy. Such increased responses in the pancreatic flow to antral distension after both vagotomy and splanchnicectomy are shown to be eliminated by tight ligature around the pyloric region, but not by caeliac and superior mesenteric ganglionectomies. The results indicate that besides the long route vago-vagal reflex, there is also a short route reflex from the antrum to the pancreas. In this study, the pyloric sphincter was occluded by submucosal ligature to prevent gastric fluid flow into the duodenum and to maintain the intramural nervous pathway in the seromuscular layer in the pylorus. The nervous pathway of the short route reflex may cross the surface or seromuscular layer of the pyloric sphincter and an oral portion of the duodenum on its way to pancreatic exocrine cells. Since such a short route reflex is abolished by hexamethonium of atropine sulfate, the reflex may have a cholinergic and muscarinic nature, and be mediated via a nerve cell station whose possible sites would be 
either the intrapancreatic ganglia as postulated in the duodenopancreatic short reflex (Tiscornia et al., 1976) or the submucous and Auerbach plexus in the antrum, but not the prevertebral ganglion.

BLAIR et al. (1966) found in chloralose anesthetized and splanchnicectomized cats that chemical and mechanical stimulation of the antrum produced a humorally mediated increase in pancreatic enzyme secretion after vagotomy. We, however, found no humorally mediated response in the pancreas to antral distension after making an external ligature around the pyloric sphincter in vagotomized dogs. In their study, the pylorus was occluded with a tape ligature. The discrepancy may be due to the difference in the ligature methods rather than the species difference. Presumably, an incomplete interruption of the short reflex pathways would occur in cases of a tape ligature.

DeBas and YAmaGishi (1978) reported that the pancreatic protein response in conscious dogs after alkali distension of the antral pouch remained after vagotomy, though it was only $10 \%$ of the pre-vagotomy value. However, in the present study, at least in vagotomized dogs, no rise in the serum gastrin concentration occurred after antral distension with Tyrode's solution, so the effect of gastrin on pancreatic secretion can be denied. This discrepancy may be due to the difference between conscious dogs and anesthetized or decerebrated dogs. In conscious dogs, gastrin release may participate in cephalic and gastric phases of the pancreatic response, but its relative contribution is not certain (PrESHAw et al., 1965a, b; OrAFOOD et al., 1972; CSENDES et al., 1972; DeBAS et al., 1976; ROSENBERG et al., 1976; IMPICCIATORE et al., 1977; Debas and Yamagishi, 1978; FoKina et al., 1979; Guzman et al., 1980; JOHNSON et al., 1982). Further, it was shown that rhythmic pancreatic secretion occurred following spontaneous forceful antral contractions after splanchnicectomy in vagotomized dogs, and it was completely abolished by tight ligature around the pyloric sphincter from the serosal side in spite of a continuance of antral contractions. It is most likely that this pancreatic response is induced via the same short route reflex.

Concerning gastrointestinal hormones besides gastrin, there are some reports that vagal efferent stimulation caused no significant increase in plasma secretin in dogs (CHEY et al., 1979) and in pigs (HoLST et al., 1979), or in the CCK-PZ concentration in calves (ADRIAN et al., 1983) and in dogs (GUZMAN et al., 1979). So, the participation of such hormones in the antro-pancreatic response may be excluded, although in the present study, they were not measured.

A question arises as to whether the pancreatic response by the short reflex may be due to the increased secretin and/or CCK-PZ released from the duodenal mucous. However, this possibility seems unlikely for the following reasons: 1) The latency in the short route reflex was short (about $1 \mathrm{~min}$ ) and the response disappeared within a few minutes after cessation of antral distension (see Fig. 4A). In dogs, however, the latency of the response of pancreatic outflow due to increased secretin release caused by intraduodenal injection of $30-50 \mathrm{ml}$ of $0.4 \% \mathrm{HCl}$ is about 2 min (Bayliss and Starling, 1902). Singer et al. (1980) also reported in 
vagotomized dogs that the latencies of the increased amylase output due to CCK release by intraduodenal stimulants, sodium oleate and tryptophan, are about 3 min. 2) There are some differences in the time courses of the responses by the short reflex and endogenous secretin. The pancreatic outflow following the intraduodenal injection of $\mathrm{HCl}$ gradually increases and reaches rapid flow 4 min after stimulation begins (BAYLISS and STARLING, 1902), but the flow in the short reflex reaches the rapid flow at the second or third drop. Further, periodic increased pancreatic outflow following marked antral contractions is frequently observed in the short reflex (see Figs. 4A, 6A), but not duodenomucosal stimulation. 3) There are no reports that secretin and CCK-PZ are released by nervous action.

However, whether or not secretin and/or CCK-PZ release are elicited by antral distension is a problem requiring further study.

Sympathetic effects on pancreatic secretion are not clearly understood. Both inhibitory and excitatory actions have been reported (BABKIN et al., 1939; Elisha et al., 1984). In this study, the increased response to antral distension after vagotomy alone was significantly smaller than that after vagotomy and splanchnicectomy. So, the pancreatic response may be suppressed by a sympathetic nerve, although the details of such suppression were not studied. Pancreatic secretion responded in two ways to distension of the oesophagus. One response was an increase due to the vago-vagal reflex, and the other response was a decrease by the vago-sympathetic reflex (FuruKawa, 1986). However, in this study, no decrease in pancreatic secretion in response to antral distension was recognized.

This study was supported by a project grant from Kawasaki Medical School.

\section{REFERENCES}

Adrian, T. E., Bloom, S. R., and Edwards, A. V. (1983) Neuroendocrine responses to stimulation of the vagus nerves in bursts in conscious calves. J. Physiol. (Lond.), 344: 25-35.

BABkin, B. P. (1924) The influence of the blood supply on pancreatic secretion. J. Physiol. (Lond.), 59: 153-163.

Babkin, B. P., Hebi, C. O., and Sergeyeva, M. A. (1939) The parasympathetic-like effect of splanchnic nerve stimulation on pancreatic secretion. Q. J. Exp. Physiol., 29: 217-237.

Bayliss, W. M. and Starling, E. H. (1902) The mechanism of pancreatic secretion. $J$. Physiol. (Lond.), 28: 325-353.

Blair, E. L., Brown, J. C., Harper, A. A., and Scratcherd, T. (1966) A gastric phase of pancreatic secretion. J. Physiol. (Lond.), 184: 812-824.

CheY, W. Y., Kim, M. S., and LeE, K. Y. (1979) Influence of the vagus nerve on release and action of secretin in dog. J. Physiol. (Lond.), 293: 435-446.

Csendes, A., Walsh, J. H., and Grossman, M. I. (1972) Effects of atropine and of antral acidification on gastrin release and acid secretion in response to insulin and feeding in dogs. Gastroenterology, 63: 257-263. 
Debas, H. T., Walsh, J. H., and Grossman, M. I. (1976) After vagotomy atropine suppresses gastrin release by food. Gastroenterology, 70: 1082-1084.

Debas, H. T. and Yamagishi, T. (1978) Evidence for pyloropancreatic reflex for pancreatic exocrine secretion. Am. J. Physiol., 234: E468-E471.

Elisha, E. E., Hutson, D., and Scratcherd, T. (1984) The direct inhibition of pancreatic electrolyte secretion by noradrenaline in the isolated perfused cat pancreas. J. Physiol. (Lond.), 351: 77-85.

Fokina, A., KontureK, S. J., K wiecien, N., and Radecki, T. (1979) Role of gastric antrum in gastric and intestinal phases of gastric secretion in dogs. J. Physiol. (Lond.), 295: 229-239.

Furukawa, N. (1986) Effects of oesophageal distension on the canine pancreatic exocrine secretion. Jpn. J. Smooth Muscle Res., 22: 21-29.

Furukawa, N. and OKaDA, H. (1985) The exocrine pancreatic reflex following distension of the canine gastric pylorus. J. Physiol. Soc. Jpn., 47: 590.

Guzman, S., Chayvislle, J.-A., Banks, W. A., Rayford, P. L., and Thompson, J. C. (1979) Effect of vagal stimulation on pancreatic secretion and on blood levels of gastrin, cholecystokinin, secretin, vasoactive intestinal peptide and somatostatin. Surgery, 86: 329-336.

Guzman, S., Lonovics, J., Hejtmancik, K. E., Gomez, L., Payford, P. L., and Thompson, J. C. (1980) Role of gastrin in vagally-stimulated pancreatic secretion. Ann. Surg., 191: $35-39$.

Holst, J. J., Schaffalitzky De Muckadell, O. B., and Fahrenkrug, J. (1979) Nervous control of pancreatic exocrine secretion in pigs. Acta Physiol. Scand., 105: 33-51.

Impicciatore, M., Walsh, J. H., and Grossman, M. I. (1977) Low doses of atropine enhance serum gastrin response to food in dogs. Gastroenterology, 72: 995-996.

Johnson, C. D., Sarles, H., and Treffot, M. J. (1982) The effect of antral vagal denervation on gastrin release and pancreatic secretion in response to 2-deoxyglucose in conscious dogs. J. Physiol. (Lond.), 325: 50P-51P.

OKadA, H. and Furukawa, N. (1984) The oxyntomucosal pancreatic secretion reflex in dogs. Auton. Nerv. Syst. Jpn., 21: 452-459.

Orafood, R. C., Beesley, W. H., Dutta, P., Yanagisawa, T., and Eisenberg, M. M. (1972) The critical nature of gastrin in pancreatic exocrine secretion in dogs. Surgery, 72: $42-52$.

Preshaw, R. M., Cooke, A. R., and Grossman, M. I. (1965a) Pancreatic secretion induced by stimulation of the pyloric gland area of the stomach. Science, 148: 1347-1348.

Preshaw, R. M., Cooke, A. R., and Grossman, M. I. (1965b) Stimulation of pancreatic secretion by a humoral agent from the pyloric gland area of the stomach. Gastroenterology, 49: 617-622.

Rosenberg, I. R., Zambrano, V. J., Janowitz, H. D., and Rudick, J. (1976) Parasympathetic innervation and pancreatic secretion: The role of the gastric antrum. Ann. Surg., 183: 247-251.

Singer, M. V., Solomon, T. E., Wood, J., and Grossman, M. I. (1980) Latency of pancreatic enzyme response to intraduodenal stimulants. Am. J. Physiol., 238: G23-G29.

Tiscornia, O. M., Sarles, H., Voirol, M., Levesque, D., Dzieniszewski, J., Palasciano, G., Cavarzan, A., Teixeira, A., Bretholz, A., Laugier, R., Singer, M., and Demol, P. (1976) Evidences for duodenopancreatic reflexes and an anti-CCK factor with lidocaine infused intravenously and sprayed topically on pancreatic papilla in non- 
alcoholic and alcohol-fed dogs. Am. J. Gastroenterol., 66: 221-240.

White, T. T., Lundh, G., and MAGEe, D. F. (1960) Evidence for the existence of a gastropancreatic reflex. Am. J. Physiol., 198: 725-728. 